Breaking the Link between Provocation and Aggression: The Role of Mitigating Information

\title{
Breaking the Link between Provocation and Aggression: The Role of Mitigating Information
}

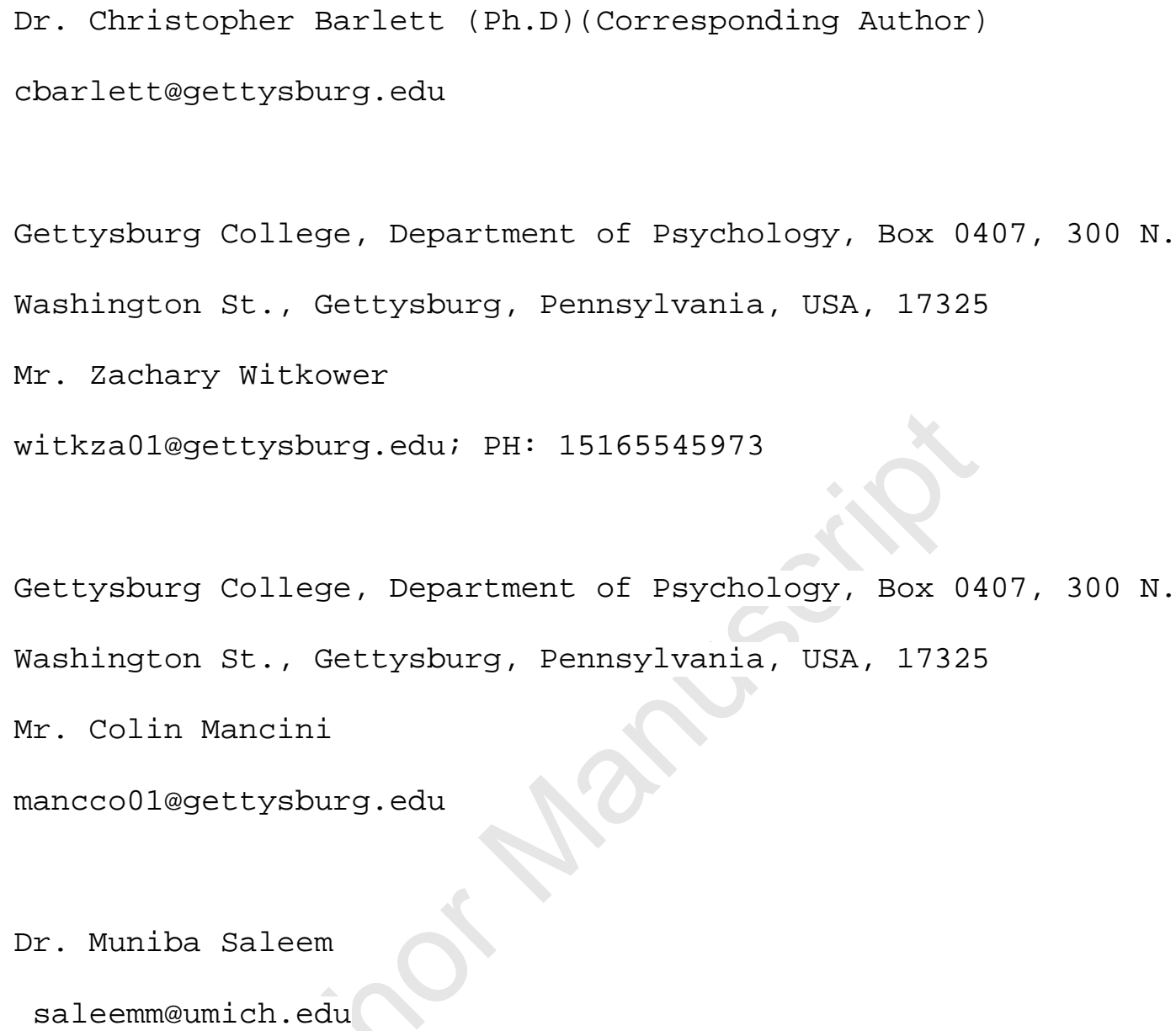

Abstract

In two experimental studies, we examine the extent to which strong or weak mitigating information after a provocation alters aggressive responding. In Study 1, we randomly assigned 215 (108 female) college-aged participants to a strong or weak provocation by having a research assistant talk to the participant about failing a task in a harsh or confused tone. This was followed 
by a second research assistant giving a strong or weak excuse to the participant regarding the first research assistant's behavior. Then, aggressive behavior was assessed using a researcher rating task. In Study 2, 63 (25 female) college-aged participants interacted with a confederate on the CRT. All participants were strongly provoked by receiving strong noise blasts. After five CRT trials, the confederate delivered weak or strong mitigating information to the participant regarding the noises blasts. The results indicated that a) strong provocations are more likely to increase aggression than weak provocations, b) strong mitigating information is more likely to decrease aggression than weak mitigating information, and c) the varying strength of mitigating information is important in situations involving weak, but not strong provocations: strong mitigating information is more likely than weak mitigating information reduce aggression when provocation is strong, but not when provocation is weak. We discuss the importance of mitigating information in decreasing aggressive behavior and the conditions in which mitigating information is especially likely to be effective.

Breaking the Link between Provocation and Aggression: The Role of Mitigating Information

How humans interpret, process, and make attributions about their world, especially interpersonal interactions, has implications for subsequent social behavior, including aggression. Multiple theoretical frameworks of aggression (e.g., Social Information Processing [Crick \& Dodge, 1996], I ${ }^{3}$ Theory [Slotter \& Finkel, 2011], General Aggression Model [GAM; Anderson \& Bushman, 2001]) emphasize the importance of higher level cognitive processing when deciding whether to aggress after a perceived provocation. Few research studies have examined how the strength of environmental cues, such as mitigating information statistically and 
theoretically interact with provocations to influence aggression. Here, mitigating information are factors that change an initially hostile attribution after a provocation into one that is less personally threatening, such as excuses, justifications, and/or apologies (Barlett \& Anderson, 2011). The current research consists of two experimental studies that test whether the strength of provocations and mitigation information interact to influence subsequent aggression.

\section{Mitigating Information and Aggression}

After a perceived provocation, it may be commonplace for the provocateur to apologize, state that their behavior was accidental, or justify their behavior. While research reveals that provocations often lead to aggressive behavior (c.f., Anderson \& Huesmann, 2003), mitigating information may function to reduce such behavior (Barlett \& Anderson, 2011; Dyck \& Rule, 1978; Johnson \& Rule, 1986; Ohbuchi, Kameda, \& Agarie, 1989; Krieglmeyer et al., 2009; Zillmann \& Cantor, 1976; Younger \& Doob, 1978). In other words, mitigating information is likely to moderate the effect of a provocation on aggression. Indeed, a meta-analysis by Barlett (2013) found that providing mitigating information to provoked participants significantly reduced the likelihood of aggressive behavior across 24 effect size estimates. Although this effect is small, $(r=-.10$ [95\% CI: -.14 to -.06$], p<.001)$, it does reveal that mitigating information is negatively related to aggression.

Additional work has established the psychological processes that are likely to be changed as a function of providing mitigating information. For instance, Barlett and Anderson (2011) showed that mitigating information (in the form of an excuse) can redirect vengeance from the provocateur to the excuse, and others have shown that mitigating information can manage impressions (Ohbuchi et al., 1989), reduce retaliation (Zechmeister, Garcia, Romero, \& Vas, 2004), and alter attributions made to the provocateur (Bushman, Baumeister, \& Phillips, 2001). 
Mitigating information is consistently related to a reduction in aggression (Barlett, 2013) independently of the mediating mechanisms involved.

\section{Theoretical Underpinnings}

The postulates of the General Aggression Model (GAM; Anderson \& Bushman, 2002) outline the underlying psychological processes that occur when mitigating information is successful in reducing the likelihood of subsequent aggression after a provocation. Situational (e.g., provocation) and personality input variables are likely to interact to influence the present internal state, which consists of inter-correlated aggressive affect, aggressive cognitions, and physiological arousal. Any one or combination of these internal state variables alters subsequent appraisal and decision processes. A provoking situation activates a heightened internal state in which the perceiver's immediate appraisal is to attribute the target's behavior as hostile. If the person has available cognitive resources, re-appraisal processes are likely to be engaged, and, if successful, will decrease the aggressive response. Here, cognitive resources refer to time, motivation, and cognitive ability and re-appraisal is defined as seeking out additional information to clarify one's thoughts or the environment (Barlett \& Anderson, 2011). These appraisal and decision processes are the immediate precursor to impulsive or thoughtful aggressive or non-aggressive behavior.

Anderson and Bushman (2002) posited that such processes are not ubiquitous across situations. Indeed, Barlett (2013) found that the effect of mitigating information on aggression after a provocation is moderated by several context-specific variables. First, when the provocation is strong, mitigating information is unlikely to reduce aggression, a finding that makes theoretical and practical sense. Second, when the mitigating information is weak (or insufficient) aggression is likely. Overall, strong provocations are likely to result in aggressive 
behavior as long as they are not paired with strong pieces of mitigating information. Beyond these moderating effects found by Barlett (2013), we are unaware of any published empirical study that has explicitly tested whether the strength of mitigating information must exceed the strength of a provocation to reduce aggression: the purpose of the current research.

\section{Overview of the Current Research}

Two studies were conducted to test whether provocation and mitigating information strengths interact to affect aggression. In Study 1, all participants failed a task and then were given a strong or weak provocation by the experimenter. Directly after the provocation an additional experimenter delivered the strong or weak excuse before assessing aggression towards the provocateur. In Study 2, we used a within-subjects design where all participants were harshly provoked by a confederate. Then, participants were randomly assigned to receive a weak then strong excuse or a strong then weak excuse. Aggression was assessed three times throughout the procedure. In both studies, we predicted that aggression would be highest when participants were strongly provoked but given the weak excuse, and in all other provocation-excuse combinations, aggression would be similar.

\section{Study 1}

The purpose of Study 1 was to determine whether the strength of mitigating information has to exceed the strength of a provocation in order to reduce aggressive behavior. Based on theory (Anderson \& Bushman, 2002) and past work (Barlett, 2013) we predicted that both strong and weak mitigating information will be sufficient to reduce aggression after a weak provocation; however, when the strong provocation is given, aggression will only be reduced when coupled with strong, rather than weak, mitigating information.

\section{Method}




\section{Participants}

Two hundred and fifteen (108 female) students from a small Eastern liberal arts college participated in the current study for partial course credit in their psychology class. The average age of the sample was $18.62(S D=2.08)$ years. The majority were Caucasian $(77.6 \%)$, which is typical of the college. A majority were in their first year of their undergraduate education $(72.4 \%)$.

\section{Materials}

Aggression. To measure aggressive behavior, we adapted an experimenter rating form used by Dill and Anderson (1995). Participants rated the experimenter on a variety of positive dimensions (i.e., intelligent, skillful, competent, helpful, kind, warm, responsible, and hirable) using a 1 (strongly disagree) to 7 (strongly agree) rating scale. Participants were told that the research assistant had applied to work in the lab for another semester and their evaluation of the research assistant would have bearing on whether they get hired for another semester or not. Thus, negative ratings for the research assistant would hurt their chances of getting re-hired and served as our assessment of aggressive behavior. All these items were reverse scored before being summed, such that higher scores indicate higher levels of aggressive behavior. This scale had an excellent reliability in the current study $(\alpha=.94)$.

Experimental Tasks. We created two tasks for the provocation and excuse manipulations. First, participants were asked to solve a maze using their non-dominant hand while keeping their drawn lines inside the maze. Once that was completed, participants were asked to copy a paragraph about horses on a sheet of paper using their non-dominant hand. Participants were instructed to complete both tasks in five minutes; however, we pilot tested these tasks and they were unsolvable in that amount of time. These tasks were not the 
provocation or mitigating information; however, they were used to set up the provocation and mitigating information administration (see Procedure).

Task Frustration. A single item assessed the extent to which both the tasks were frustrating. After completing both tasks, participants were asked to indicate how difficult these tasks were on a 1 (very slightly or not at all) to 5 (extremely) rating scale. Higher scores indicated more state-level frustration.

Suspicion Measure. At the end of the study, participants were asked various questions to assess whether they were suspicious about the procedures or measures in the study. $21 \%$ of the sample was excluded for being overly suspicious. This left 169 (90 female) participants with an average age of $18.56(S D=2.26)$. The sample consisted of primarily Caucasians $(80.3 \%)$. Students were in their first year of undergraduate education (73\%). There was no difference between those excluded and those retained for aggression, age, or frustration ( $t \mathrm{~s}<1.30, p \mathrm{~s}>$ .20). There was also no difference between those excluded vs. retained for sex, $\chi^{2}=2.28, p>.10$, provocation condition, $\chi^{2}=2.67, p>.10$, or excuse condition, $\chi^{2}=3.45, p=.06$.

Demographics. A demographic questionnaire was used to assess age, sex, ethnicity, and year in school.

\section{Procedure}

Upon completion of the informed consent, participants were greeted by two research assistants. One assistant was acting as the novice research assistant (inexperienced RA) and the other was the experienced RA. RAs were selected such that the inexperienced RA (the provocateur) was the same sex as the participant to control for sex-effects towards the target (Bettencourt \& Kernahan, 1997). The experienced RA explained that s/he is training the inexperienced RA and will supervise while the inexperienced RA conducts his/her independent 
research project. The experienced RA stepped to the side, and the inexperienced RA explained that the study is about how people process various tasks. The inexperienced RA first had the participant complete several questionnaires including the demographic questionnaire ${ }^{1}$. Once the questionnaires were completed the inexperienced RA returned to the room, explained the two experimental tasks (completing a maze with their non-dominant hand while keeping their writing utensil inside the maze lines and copying a poem about a horse to a sheet of paper with their nondominant hand), and gave the participant five minutes to complete both tasks. The participant was told that these tasks were pilot tested, and should not take them more than five minutes to complete (in reality these tasks could not be completed successfully in five minutes). After five minutes had elapsed, the inexperienced RA came back into the room and delivered the randomly assigned provocation manipulation. Participants who were strongly provoked were told, "You didn't finish? You messed up my study. Really, how hard is it to do these simple tasks?" in a frustrated tone. Participants in the weak provocation condition were told, "You didn't finish? Did you not understand the instructions?" in a confused tone.

After the participants received their respective provocation statements, the inexperienced RA asked the participants to fill out some questionnaires on the computer while s/he tried to figure out what to do next, and left the room. Here, the participant completed several questions including the task frustration item ${ }^{2}$. When these were completed, the experienced RA entered the

\footnotetext{
${ }^{1}$ Participants completed measures of need for cognition (Cacioppo, Petty, \& Kao, 1984), trait aggression (Buss \& Perry, 1992), trait re-appraisal (Gross \& John, 2003), and social competence (Robinson, Fetterman, Hopkins, \& Krishnakumar, 2013). Results showed that state aggression was only correlated with the trait aggression measure, $r=.19, p<.05$. As per a reviewer suggestion, we tested the excuse $\mathrm{X}$ provocation $\mathrm{X}$ trait re-appraisal effect on state aggression. Results showed that none of the two-way interactions or the three-way interaction was significant ( $p$ s $>$.05). In addition, trait re-appraisal did not correlate with aggression, $r=-.03, p=.74$. Therefore, none of these effects were explored further.

${ }^{2}$ In addition, we had participants complete the state hostility scale (Anderson, Deuser, \& DeNeve, 1995) and the Positive Affect Negative Affect Schedule (Watson, Clark, \& Tellegen, 1988). Two one-way ANOVAs showed nonsignificant differences between the weak and strong provocation conditions on state hostility and negative affect,
} 
room and explained that s/he will be finishing the study. Participants who got the strong excuse where then told, "S/he was told to be mean to you on purpose for this study", whereas participants who got the weak excuse were told, "S/he doesn't really mean to sound irritated with you."

Next, the experienced RA explained the aggression measure and made sure to emphasize that the survey was anonymous and the answers had implications for whether the new RA would continue in the lab as a research assistant. Finally, the experienced RA entered the room, administered the suspicion measure, and then both RAs thanked and fully debriefed the participant.

\section{Results}

A 2 (excuse: strong, weak) X 2 (provocation: strong, weak) analysis of covariance (ANCOVA) was conducted with aggressive behavior as the dependent variable and task frustration as the covariate. Results showed a significant main effect of provocation, $F(1,152)=$ 4.04, $p<.05, \eta_{p}^{2}=.03$. Participants who were strongly provoked were more aggressive $(M=$ $22.78, S E=1.04)$ than those who were given the weak provocation $(M=19.93, S E=.96)$. There was also a significant main effect of excuse, $F(1,152)=8.57, p<.01, \eta^{2}{ }_{p}=.05$. Participants who were given the weak excuse $(M=23.43, S E=1.03)$ were more aggressive than those who received the strong excuse $(M=19.28, S E=.97)$. However, these effects were qualified by a significant excuse $\mathrm{X}$ provocation interaction, $F(1,152)=4.20, p<.05, \eta_{p}^{2}=.03$. A simple effects analysis was used to probe this interaction and revealed that when the provocation was weak, no significant difference was found between the weak vs. strong excuse, $F(1,152)=.41, p>.05$; however, when the provocation was strong, participants who were given the weak excuse were

Fs $<1.6, p s>.20$ ), which is common since both the weak and strong provocations were, in fact, provocations. These scales were not analyzed further. 
significantly more aggressive than those who were given the strong excuse, $F(1,152)=11.50, p$ $<.01, \eta_{p}^{2}=.07$ (see Figure 1).

\section{Discussion}

We predicted that both strong and weak mitigating information would be sufficient to reduce aggression after a weak provocation, but strong mitigating information would be required to reduce aggression after a strong provocation. Results from Study 1 were consistent with our hypotheses. Indeed, when there was a strong provocation, strong mitigating information significantly reduced aggression compared to weaker information. However, if the provocation was weak, there was no significant difference in aggression.

\section{Study 2}

Study 2 was conducted to conceptually replicate the findings of Study 1 using a different measure of aggressive behavior and different weak and strong excuses. Additionally, the excuses were administered by the provocateur, rather than the experimenter. Study 2 utilized only a strong provocation to help isolate the effects found in Study 1.

\section{Method}

\section{Participants}

Sixty-three (25 female) students from a small Eastern liberal arts college participated in the current study for partial course credit in their psychology class. The average age of the sample was $19.00(S D=.90)$ years. The majority of the sample consisted of Caucasian $(87.3 \%)$ students in their first year of their undergraduate education $(66.7 \%)$.

\section{Materials}

Aggression. The Competitive Reaction Time (CRT) task was used to assess aggressive behavior, which is widely considered to be a valid measure (e.g., Giancola \& Zeichner, 1995). 
Participants were asked to hit the spacebar on a computer keyboard as soon as they heard an auditory tone, which was played through headphones connected to the computer. Participants were told that this is a reaction time game and they were competing with another participant in this task to see who will hit the spacebar first. If they win, they would administer a noise blast to the other participant. However, if they lost, they would receive a noise blast from the other participant. Before each trial, participants were asked to select a noise blast level to give to their opponent if they were to win the reaction time game. These noise blasts included ten levels, including 0 (60db), 1 (65db), 2 (70db), 3 (75db), 4 (80db), 5 (85db), 6 (90db), 7 (95db), 8 (100db), and 9 (105db). We adapted the CRT in several ways for the purposes of the current study. First, all participants lost the first trial. Second, after the fifth trial an error message was displayed saying “e-prime internal error \#5037 - contact your network administrator”. Third, all participants were told that they received the noise blasts selected by the confederate that were high noise intensities after a loss $(95 \mathrm{db}$ and $100 \mathrm{db})$. This is how we made sure that all participants were strongly provoked. Additionally, participants were told the intensity that the confederate selected (although not administered) after a winning trial (105db), further reinforcing the strong provocation.

Trait Aggression. The 29-item Aggression Questionnaire (Buss \& Perry, 1992) was used to assess trait aggression. Participants responded to statements using a 1 (extremely uncharacteristic of me) to 7 (extremely characteristic of me) rating scale. A sample item includes, "Once in a while, I cannot control the urge to strike another person." Two items were reverse scored prior to summing, such that higher scores indicate higher levels of trait aggression $(\alpha=.90)$. 
Suspicion Measure. At the end of the study, participants were asked various questions to assess whether participants were suspicious about the procedures or measures in the study. $27 \%$ of the sample reported being overly suspicious, and were therefore excluded. This left 46 (18 female) participants with an average age of $18.96(S D=.87)$. The majority of the sample consisted of Caucasian (89.2\%) students who were in their first year of undergraduate education $(71.7 \%)$. There was no difference between those excluded and those retained for aggression $(t \mathrm{~s}<1.10, p \mathrm{~s}$ $>$.20). There was also no difference between those excluded vs. retained for sex, $\chi^{2}=.02, p>$ .10 or excuse order, $\chi^{2}=.16, p>.10^{3}$.

Demographics. A demographic questionnaire was used to assess age, sex, ethnicity, and year in school.

\section{Procedure}

Upon completion of the informed consent, each participant and a same sex confederate were greeted by the researcher and told that they would be completing a reaction time game with each other. The CRT was explained to the participant and confederate simultaneously and each got to hear three sounds of varying intensity $(75 \mathrm{db}, 85 \mathrm{db}, 95 \mathrm{db})$ before going to separate lab rooms. The CRT was played for five trials. After the fifth trial, the CRT was rigged so it would stop working and an experimenter-generated error message prompted the participant to tell the researcher running the study. Both the participant and confederate left their respective room at the same time to inform the researcher that the CRT stopped working. Here, participants were randomly assigned to receive the weak or strong excuse first. While the researcher was "fixing" the CRT, participants who received the weak excuse were told by the confederate, "I hope that the noise wasn't too loud....I'm just having a bad day." Participants who received the strong

\footnotetext{
${ }^{3}$ As expected, when the entire sample was included, the block $X$ order interaction was no longer significant; however, the trial $\mathrm{X}$ order interaction remained significant.
} 
excuse were told by the confederate, "My computer was weird. I was trying to hit a 2 or 3 and it wouldn't register so I had to pick a high number. I am so sorry I gave you harsh noises. I hope I didn't hurt you or anything." Then, the researcher asked the participant and confederate to play the CRT again. Identical to before, the CRT fails after the fifth trial and the confederate delivers the other excuse to the participant. The CRT is "fixed" for a second time, and then played for five more trials. After the third round of five trials, when the CRT stops working again, the researcher instructs the participant and confederate to stop with the CRT since it is broken and to fill out some questionnaires instead, including the demographic and trait aggression questionnaires. After these questionnaires were completed, participants were given the suspicion check, thanked, and fully debriefed.

\section{Results}

As our primary analysis, a 3 (block: first 5 trials, second 5 trials, third 5 trials) X 2 (order: strong then weak excuse, weak then strong excuse) mixed ANCOVA was conducted controlling for trait aggression with block as the within subjects factor. Results showed a significant twoway interaction, $F(2,56)=3.63, p<.04, \eta^{2}{ }_{p}=.12$. A simple effects analysis showed no significant main effects of order at Block $1, F(1,56)=1.15, p>.05$, or Block $3, F(1,56)=.60, p$ $>$.05. However, aggression was significantly higher at Block 2 for those who received the weak compared to the strong excuse, $F(1,56)=6.97, p<.05, \eta^{2}=.11$ (see Figure 2).

As a secondary analysis, rather than analyzing each block we analyzed the first trial of each block using an analysis identical to before. Several researchers have used the first trial of the CRT to indicate unprovoked aggression (e.g., DeWall, Bushman, Giancola, \& Webster, 2010). Results showed a significant two-way interaction, $F(2,60)=3.50, p<.04, \eta^{2}=.11$. A simple effects analysis showed that there was no significant main effect of order at Trail 1 , 
$F(1,60)=.64, p>.05$, or Trial $11, F(1,56)=.65, p>.05$. However, aggression was significantly higher at Trial 6 for those who received the weak compared to the strong excuse, $F(1,60)=$ $12.37, p<.05, \eta_{p}^{2}=.16$ (see Figure 3).

\section{Discussion}

Study 2 further unpacked the effect of varying mitigating information after a strong provocation. The experimental design systematically manipulated mitigating information strength using a within-subject design to analyze aggression, while also investigating how the successive order of the delivered information altered aggression. Furthermore, Study 2 advances the findings from Study 1 by showing that mitigating information delivered by the provocateur, in addition to excuses from a third party (as in Study 1), can decrease aggression after a strong provocation.

\section{General Discussion}

The present research shows that mitigating information can decrease aggression after a strong provocation, regardless of whether such mitigating information is administered by the provocateur or a third person; however, the mitigating information must exceed the strength of the provocation to be effective. Given the strong link between provocation and aggression (c.f., Anderson \& Huesmann, 2003), it is significant that strong pieces of mitigating information delivered post-provocation can reduce the likelihood of an aggressive response. By experimentally manipulating both the strength of the mitigating information and provocation, we were able to uncover the conditions in which aggressive behavior is reduced. We found that the strength of mitigating information is important in reducing aggression when provocation is strong, but not when it is weak. Strong provocations paired with strong mitigating information 
can reduce aggression; however, when the same provocation is coupled with weak mitigating information, aggression is unchanged.

\section{Theoretical Implications}

The current study adds to our understanding of conditions in which mitigating information can reduce aggressive behavior. Barlett (2013) found that the effect of mitigating information on aggression is moderated by the strength of the provocation and the effectiveness of the mitigating information. When paired together, our results suggest that the strength of mitigating information and provocations need to be similar to alter aggression. These effects appear reliable in both studies using different measures of aggression.

These findings are consistent with the appraisal and decision making process of GAM (Anderson \& Bushman, 2002). After any provocation, participants are likely to aggress; however, this effect is exacerbated if the provocation is strong (Bettencourt \& Miller, 1996). Provocations are situational cues that increase hostile attributions and aggression (Vasquez, Denson, Pedersen, Stenstrom, \& Miller, 2005). Barlett and Anderson (2011) and others (e.g., Kreiglemeyer et al., 2009) argued that the presence of mitigation information reduces aggression because the hostile interpretation attributed to the provocateur shifts to the excuse. Both studies suggest that when the provocation is strong, a similarly strong excuse is needed to reduce aggressive behavior. In accordance with our theoretical position, this suggests that when the provocation is strong, a weak excuse is ineffective in shifting hostile attribution biases from the provocateur to the mitigating information. Whether this aggression is impulsive or thoughtful is undetermined; however, what is clear is the importance of provocation-mitigating information pairings. Finally, our findings remained robust regarding who actually delivered the mitigating information and who provoked the participant. Study 1 had the mitigating information delivered 
by a third party (not the provocateur), while the confederate in Study 2 acted as both the provocateur and the one who delivered the mitigating information. This finding suggests that a third party agent can play a role in anti-aggression interventions; however, additional work is needed to replicate this finding.

\section{Limitations and Future Work}

There are a few limitations in the present research that should be addressed with future work. First, we did not assess any possible mediating mechanisms that explain why mitigating information of differing strengths interact with provocation strength to influence aggression. A paucity of research has shown that a reduction in revenge motives (Barlett \& Anderson, 2011) and changes in hostile attribution bias (Bushman et al., 2001) may serve as mediators; however, few studies that have explored the relation between mitigating information and aggression have tested the role of underlying mediators. We suspect that variables housed in the appraisal and decision processes of the General Aggression Model are the most promising mediators. For instance, after an initially hostile attribution following a provocation the a) degree of hostility in the attribution, b) amount of time spent analyzing the attribution, c) motivations behind the attribution, d) cognitive effort spent on analyzing the attribution, and e) re-appraisal success (or failure) are all theoretically relevant mediating mechanisms that could explain the link between mitigating information and aggression. Further, if the mitigating information is strong, the ability to shift the attribution from the provocateur to the information could be another potential mediator that explains the current findings. Future work should test these, and possibly other, theoretically related variables and processes as mediators.

Second, we did not assess the role of moderating variables in the relation between mitigating information strength and provocation strength; future research should begin to test 
what personality variables are more likely to accept certain types of mitigating information to reduce aggression. Barlett and Anderson (2011) found that those low on trait re-appraisal need mitigating information after a provocation to help reduce aggression, whereas high trait reappraisers can naturally re-attribute provocations to more benign sources. There are several other possible moderators that should be considered. For instance, Meier and Robinson (2004) found a positive relationship between blame accessibility and the percent of time spent arguing - a finding not found for highly agreeable people. Other variables related to aggression, such as hostile attribution biases, trait aggression, and narcissism, may be important moderators to consider. According to the General Aggression Model, these (and other) variables should moderate the relation between mitigating information and aggression, such that highly aggressive individuals may be more likely to automatically assign a hostile attribution to a perceived provocateur independent of the mitigating information strength that is coupled with the provocation itself. Although speculative, future research should examine such effects.

Third, as we have argued, Studies 1 and 2 are predicated on the general theoretical belief that mitigating information cues re-appraisal processes. Although there is strong theoretical backing for such claims (Anderson \& Bushman, 2001); there is a lack of empirical evidence to validate this claim. Future research should create a state re-appraisal measure that would allow us to explicitly test the mediating role that re-appraisal has on these relations. Unfortunately, we are unaware of any validated measures to assess state-based re-appraisal processes.

Finally, the samples for both studies are primarily White first year college students, which limits the generalizability of these findings. Although we have no theoretical reason to believe that these results would differ if our samples were more diverse - in terms of age, 
ethnicity, or other demographics - future research should attempt to replicate these findings on different samples to test this assertion empirically.

\section{Final Remarks}

The results of the current research suggest that mitigating information, in the form of excuses, can have a significant impact on reactive aggression. However, our results also suggest that the relationship between mitigating information and aggression is partially dependent upon provocation strength. These findings add to literature exploring conditions where aggressive behavior is reduced, specifically by exploring the role of mitigating information after a provocation. Indeed, once aggression mitigation is thoroughly understood, interventions can be reframed, created, or enhanced to teach aggressive individuals how to diffuse hostile situations to, hopefully, reduce aggression. Indeed, Barlett and Anderson (2011; Study 2) showed that reappraisal training is helpful in reducing trait levels of vengeance and increasing trait levels of reappraisal - variables that have been linked to aggressive behavior. Such training is in line with the problem-solving techniques common for aggression reduction using cognitive-behavioral training (e.g., Sukhodolsky, Kassinove, \& Gorman, 2004). 
Anderson, C. A., \& Bushman, B. J. (2002). Human aggression. Annual Review of Psychology, 53, 27-51. doi:10.1146/annurev.psych.53.100901.135231.

Anderson, C. A., Deuser, W. E., \& DeNeve, K. M. (1995). Hot temperatures, hostile affect, hostile cognition, and arousal: Tests of a General Model of Affective Aggression. Personality and Social Psychology Bulletin, 21, 434-448. doi:10.1177/0146167295215002.

Anderson, C. A. \& Huesmann, L. R. (2003). Human aggression: A social-cognitive view. In M. A. Hogg \& J. Cooper (Eds.), The Sage handbook of social psychology (pp. 296-323). London: Sage Publications.

Barlett, C. P. (2013). Excuses, excuses: A meta-analytic review of how mitigating information can change aggression and an exploration of moderating variables. Aggressive Behavior, 39, 472-481. doi: 10.1002/ab.21491

Barlett, C. P. \& Anderson, C. A. (2011). Re-appraising the situation and its impact on aggressive behavior. Personality and Social Psychology Bulletin, 37, 1564-1573. doi: $10.1177 / 0146167211423671$

Bettencourt, B. A. \& Kernahan, C. (1997). A meta-analysis of aggression in the presence of violent cues: Effects of gender differences and aversive provocation. Aggressive Behavior, 23, 447-456. doi:10.1002/(SICI)1098-2337(1997)23:6<447::AID$\mathrm{AB} 4>3.0 . \mathrm{CO} ; 2-\mathrm{D}$.

Bettencourt, B. A. \& Miller, N. (1996). Gender differences in aggression as a function of provocation: A meta-analysis. Psychological Bulletin, 119, 422-447. doi:10.1037/00332909.119.3.422. 
Bushman, B. J., Baumeister, R. F., \& Phillips, C. M. (2001). Do people aggress to improve their mood? Catharsis beliefs, affect regulation opportunity, and aggressive responding. Journal of Personality and Social Psychology, 81, 17-32. doi:10.1037/00223514.81.1.17.

Buss, A.H., \& Perry, M. (1992). The Aggression Questionnaire. Journal of Personality and Social Psychology, 63, 452-459. doi:10.1037/0022-3514.63.3.452.

Cacioppo, J. T., Petty, R. E., \& Kao, C. E. (1984). The efficient assessment of need for cognition. Journal of Personality Assessment, 48, 306-307. doi:10.1207/s15327752jpa4803_13.

Crick, N. R. \& Dodge, K. A. (1994). A review and reformulation of social informationprocessing mechanisms in children's social adjustment. Psychological Bulletin, 115, 74101. doi:10.1037/0033-2909.115.1.74.

Denson, T. F. (2015). Four promising psychological interventions for reducing reactive aggression. Current Opinion in Behavioral Sciences, 3, 136-141. doi: 10.1016/j.cobeha.2015.04.003

DeWall, C. N., Bushman, B. J., Giancola, P. R., \& Webster, G. D. (2010). The big, the bad, and the boozed-up: Weight moderates the effect of alcohol on aggression. Journal of Experimental Social Psychology, 46, 619-623. doi:10.1016/j.jesp.2010.02.008.

Dill, J. C. \& Anderson, C. A. (1995). Effects of frustration justification on hostile aggression. Aggressive Behavior, 21, 359-369. doi:10.1002/1098-2337(1995)21:5<359::AIDAB2480210505>3.0.CO;2-6. 
Dyck, R. J. \& Rule, B. G. (1978). Effect of retaliation of causal attributions concerning attack. Journal of Personality and Social Psychology, 36, 521-529. doi:10.1037/00223514.36.5.521.

Giancola, P. R. \& Zeichner, A. (1995). Construct validity of a competitive reaction-time aggression paradigm. Aggressive Behavior, 21, 199-204. doi:10.1002/10982337(1995)21:3<199::AID-AB2480210303>3.0.CO;2-Q.

Gross, J. J., \& John, O. P. (2003). Individual differences in two emotion regulation processes: Implications for affect, relations, and well-being. Journal of Personality and Social Psychology, 85, 348-362. doi:10.1037/0022-3514.85.2.348.

Johnson, T. E. \& Rule, B. G. (1986). Mitigating circumstance information, censure, and aggression. Journal of Personality and Social Psychology, 50, 537-542. doi:10.1037/0022-3514.50.3.537.

Krieglmeyer, R., Wittstadt, D., \& Strack, F. (2009). How attribution influences aggression: Answers to an old question by using an implicit measure of anger. Journal of Experimental Social Psychology, 45, 379-385. doi:10.1016/j.jesp.2008.10.003.

Meier, B. P. \& Robinson, M. D. (2004). Does quick to blame mean quick to anger? The role of agreeableness in dissociating blame and anger. Personality and Social Psychology Bulletin, 30, 856-867. doi:10.1177/0146167204264764.

Ohbuchi, K., Kameda, M., Agarie, N. (1989). Apology as aggression control: Its role in mediating appraisal of and response to harm. Journal of Personality and Social Psychology, 56, 219-227. doi:10.1037/0022-3514.56.2.219. 
Robinson, M. D., Fetterman, A. K., Hopkins, K., \& Krishnakumar, S. (2013). Losing one’s cool: Social competence as a novel inverse predictor of provocation-related aggression. Personality and Social Psychology Bulletin, 39, 1268-1279. doi:10.1177/0146167213490642.

Slotter, E. B. \& Finkel, E. J. (2011). I3 theory: Instigating, impelling, and inhibiting factors in aggression. In. P. R. Shaver (Ed.), Human aggression and violence: Causes, manifestations, and consequences (pp. 35-52). Washington DC: American Psychological Association. doi:10.1037/12346-002.

Sukhodolsky, D. G., Kassinove, H., \& Gorman, B. S. (2004). Cognitive-behavioral therapy for anger in children and adolescents: A meta-analysis. Aggression and Violent Behavior, 9 , 247-269. doi:10.1016/j.avb.2003.08.005.

Vasquez, E. A., Denson, T. F., Pedersen, W. C., Stenstrom, D. M., \& Miller, N. (2005). The moderating effect of trigger intensity on triggered displaced aggression. Journal of Experimental Social Psychology, 41, 61-67. doi:10.1016/j.jesp.2004.05.007.

Watson, D., Clark, L. A., \& Tellegen, A. (1988). Development and validation of brief measure of positive and negative affect: The PANAS scales. Journal of Personality and Social Psychology, 54, 1063-1070. doi:10.1037/0022-3514.54.6.1063.

Younger, J. C., \& Doob, A. N. (1978). Attribution and aggression: The misattribution of anger. Journal of Research in Personality, 12, 164-171. doi:10.1016/0092-6566(78)90092-2.

Zillmann, D. \& Cantor, J. R. (1976). Effect of timing of information about mitigating circumstances on emotion responses to provocation and retaliatory behavior. Journal of Experimental Social Psychology, 12, 38-55. doi:10.1016/0022-1031(76)90085-8. 


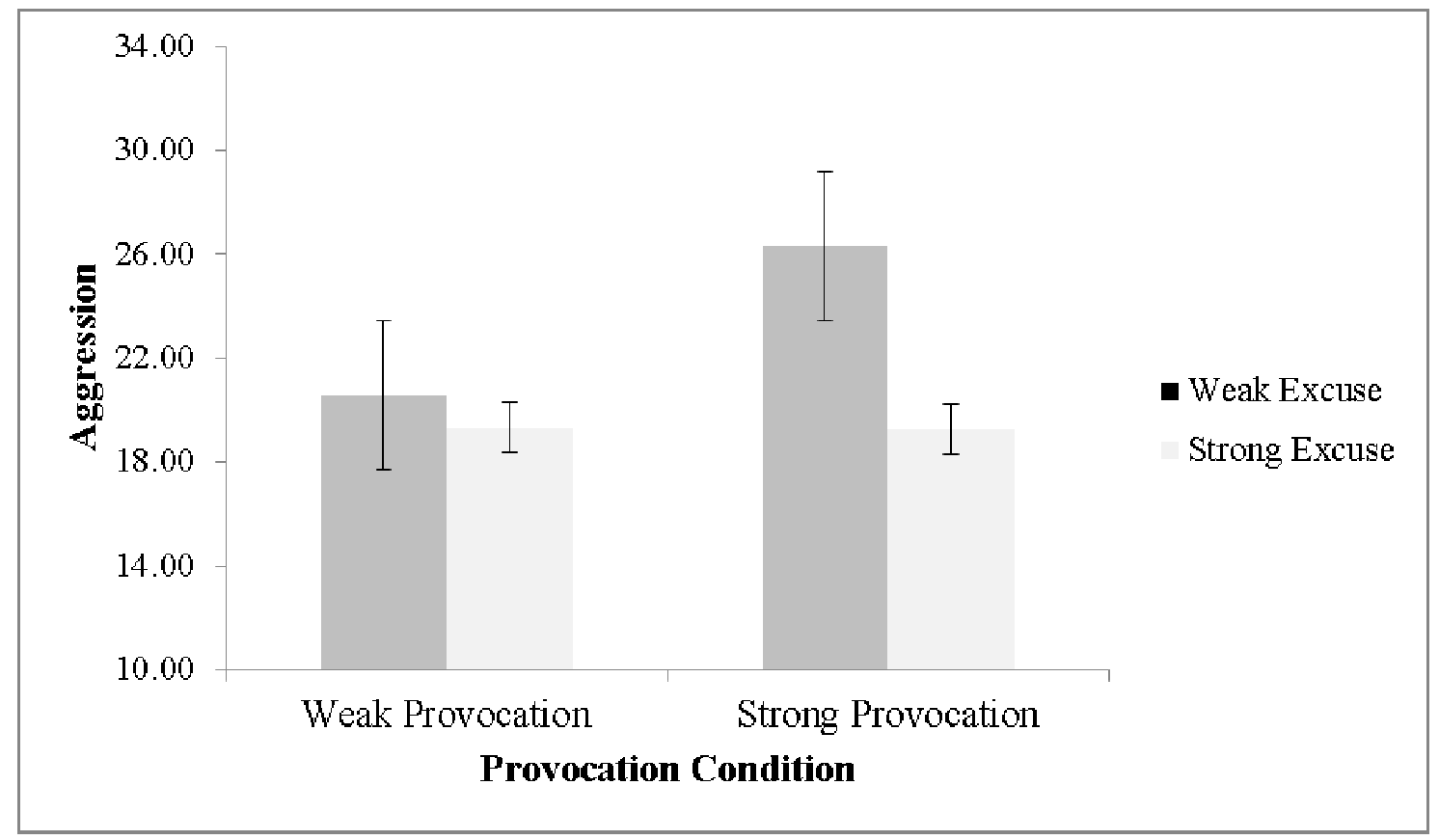

Figure 1. Mean Aggression Scores as a Function of Provocation and Excuse Strengths. Bars Represent Standard Error Around the Mean. 


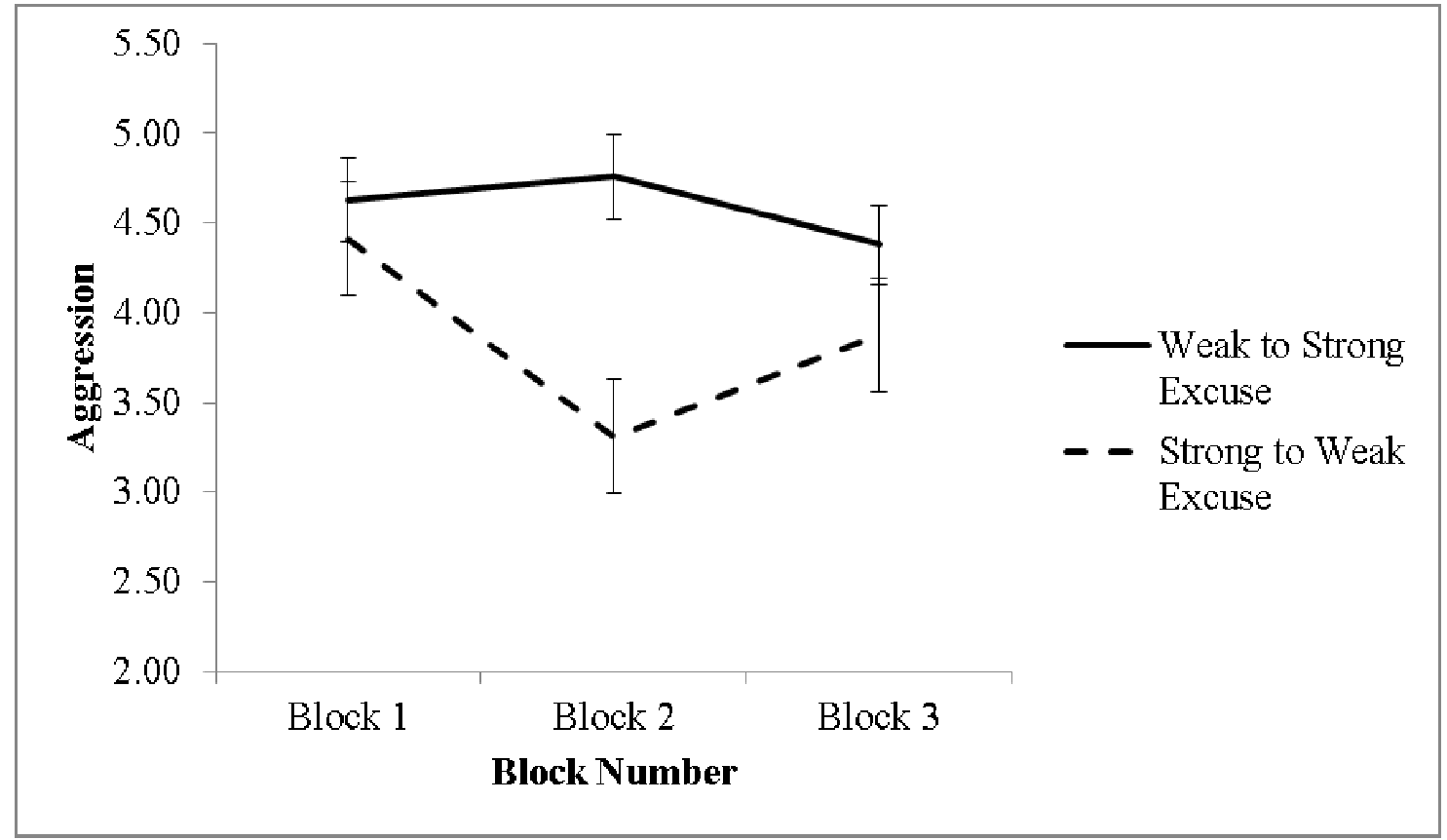

Figure 2. Mean Aggression Scores as a Function of Time and Excuse Order. Bars Represent Standard Error Around the Mean

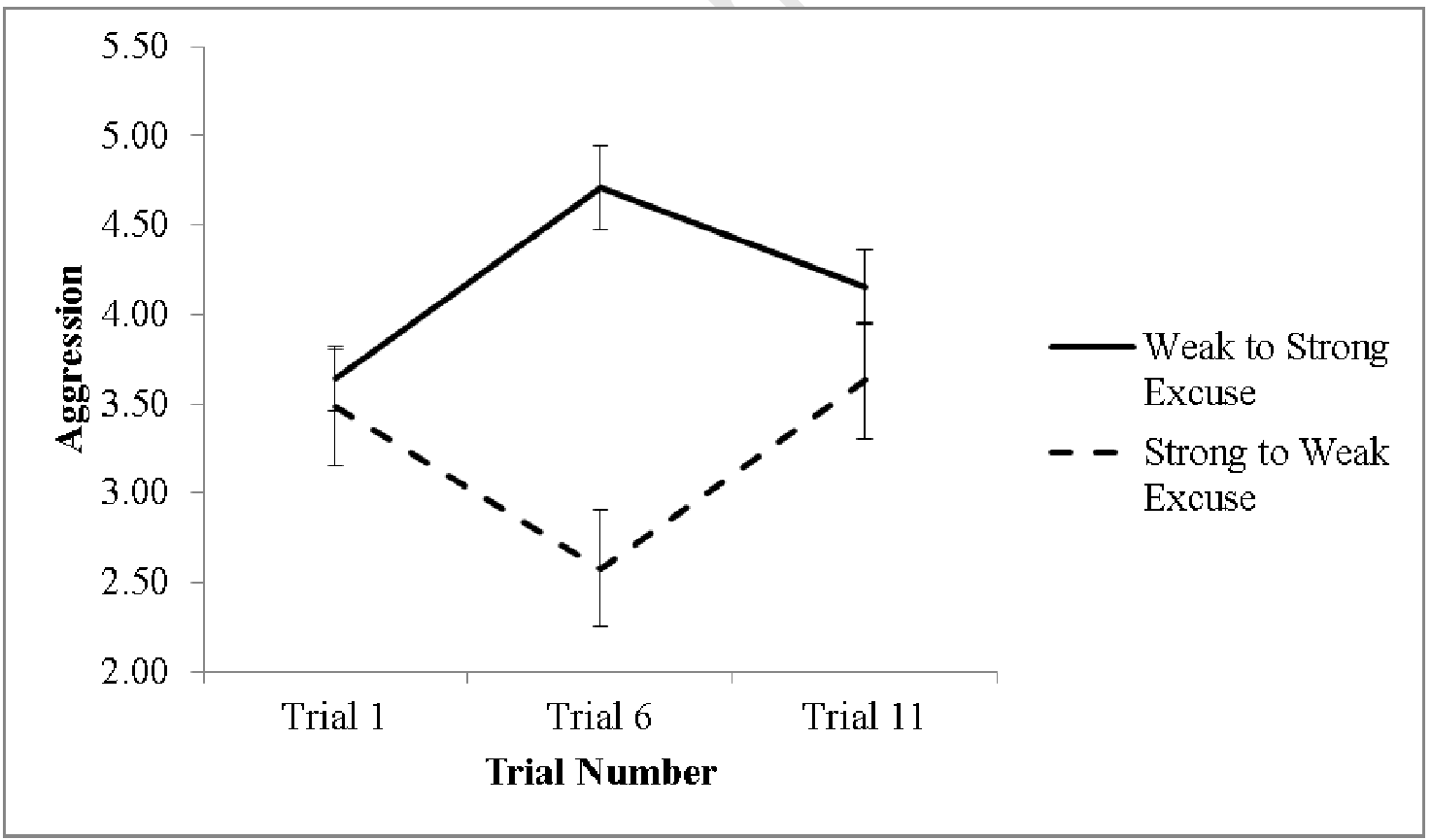


Figure 3. Mean Aggression Scores as a Function of Time and Excuse Order Using the First Trial of Every Block. Bars Represent Standard Error Around the Mean 